\title{
Genetik am Lebensweg
}

\section{Bernhard Gurtner}

Dr. med., ehemaliger medizinischer Chefarzt Spital Wetzikon, Mitglied FMH

Erinnern Sie sich an den kindlichen Schrecken, als Ihnen das doppelte Lottchen begegnete, zwei Mädchen, die von Kopf bis Fuss haargenau gleich aussahen und dieselben gelben Röcke und blauen Strümpfe trugen? Hat Ihnen Papa mit einer Schoggihasen-Metapher zu erklären versucht, wie eineiige Zwillinge entstehen? Gab es pädagogisch brauchbare Grundbegriffe der Genetik?

Nach einer Biologiestunde im Gymnasium konnte ich meinen braunhaarigen Eltern versichern, dass sie brav eine 25\%-Vererbungs-Regel des Augustinermönchs Gregor Mendel befolgt hatten. Unsere Mutter gebar zu drei fuchsrot gelockten Kindern auch ein dunkelsträhniges Mädchen. Sie bestätigte im Wochenbett, was der Gottesmann beim Erbsenzählen herausgefunden hatte, sie war Konduktorin einer dominant-rezessiven Vererbung. Der rostfarbene Schnauz des Grossvaters demonstrierte zudem den Unterschied zwischen latentem Genotyp und offensichtlichem Phänotyp.

Ein Schularzt sortierte uns in der Turnhalle nach den vererbten Blutgruppen, wobei die positiven Nuller am häufigsten waren. Nur ein Klassenkamerad stand allein in einer Ecke: AB negativ! Hat er sich geschämt oder war er als einzigartiger Appenzeller sogar stolz auf sein Hunnenblut? Was die äffischen Rhesusfaktoren bedeuten, haben wir nie ganz verstanden; wir durften aber keine negative Cousine heiraten.

In der Vorklinik zählten wir im Zoologischen Institut nachmittagelang allerlei Missbildungen an schwarzbäuchigen Taufliegen, Drosophila melanogaster. Professor Ernst Hadorn liess uns mutierte Gene auf vier Chromosomen lokalisieren mit Berechnungsformeln, die wir gleich nach dem ersten Prope wieder vergassen. Fest im Gedächtnis verblieb die DoppelhelixStruktur: Der Grasshopperclub GC und das Alte Testament AT dienen als Eselsbrücken der Basen-Paare Guanin/Cytosin und Adenin/Thymin, die wir als molekulare Klammern kennen müssen.

Für die 1953 im Wissenschaftsmagazin NATURE auf zwei Seiten beschriebene DNA-Schraube erhielten James Watson und Francis Crick 1962 gemeinsam mit dem Physiker Maurice Wilkins den Nobelpreis für Medizin. Die britische Biophysikerin Rosalind Franklin (1920-1958) wurde nicht geehrt, obwohl sie an Röntgenstrahlen-Beugungsmustern die Doppelhelixstruktur als allererste aufgeklärt hatte. Im egozentrischen

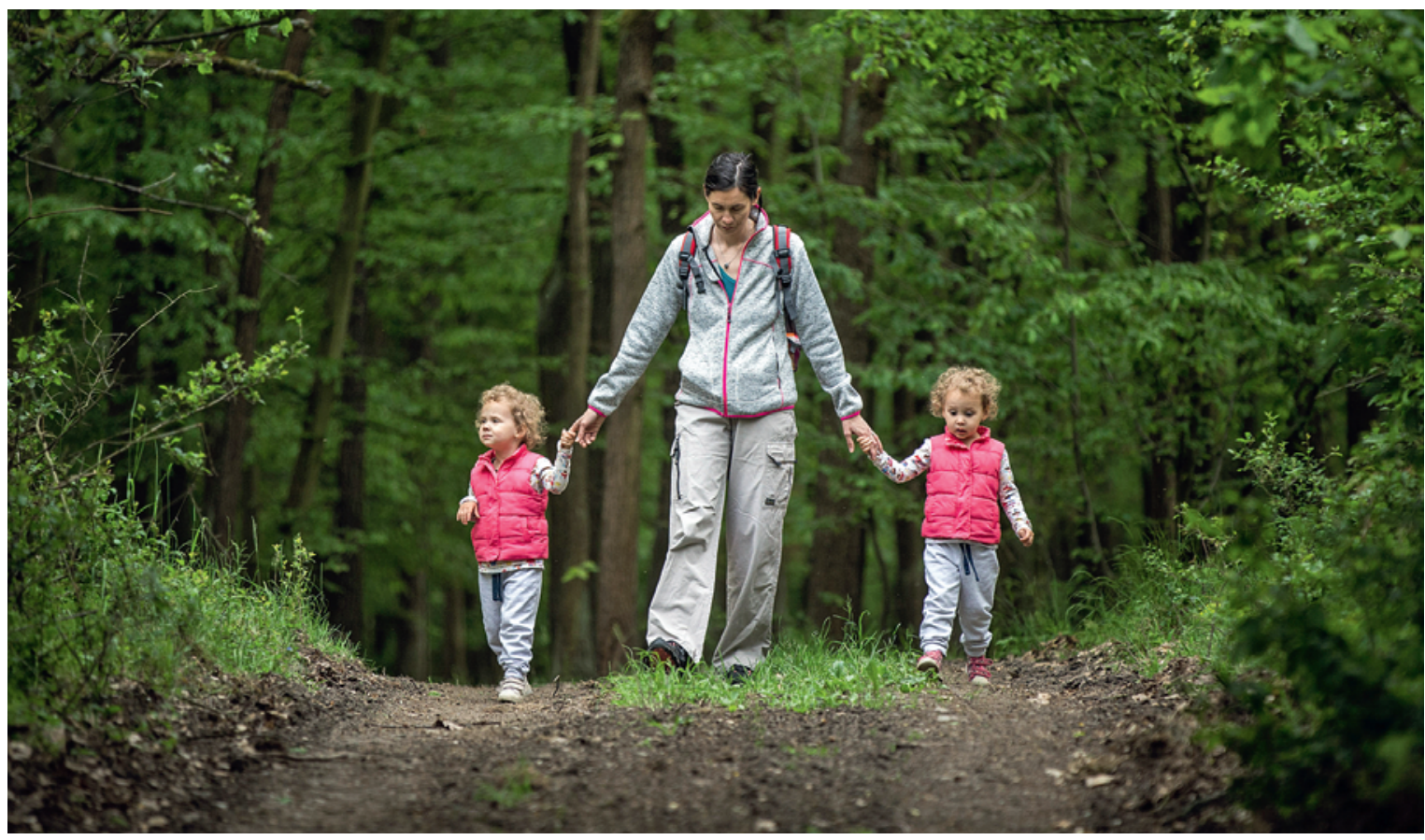

Wie erklärt man Zwillingen, weshalb sie gleich aussehen? (Symbolbild, (C) Jiri Hrebicek | Dreamstime.com) 
Bestseller «The Double Helix» war die junge Frau dem noblen Preisträger Watson auch nur eine Randnotiz wert.

In klinischen Vorlesungen wurden wir oft über seltene und eher selten über häufige Erbkrankheiten informiert. Einige akademische Dozenten brüsteten sich mit Raritäten, die sie wie in einem Zirkus vorführten. Eine mutige Kommilitonin protestierte lautstark, als ein schwer behinderter junger Mann fast nackt dem Publikum im grossen Hörsaal ausgesetzt wurde. Der geistig wache Invalide musste mithören, was an seinem Körper ganz speziell nicht normal war, welche Komplikationen drohten und wie kurz seine Lebenserwartung sei. Mit modifizierten Ultraschallgeräten, die im zweiten Weltkrieg zur Aufspürung von Unterseebooten gedient hatten, wurde es ab 1960 möglich, Geschlecht und Missbildungen von schwimmenden Föten frühzeitig zu erkennen. Unerwünschte Mädchen oder Mongoloide wurden abgetrieben - nicht nur in China. Die pränatale Diagnostik wurde perfektioniert, ethische Konflikte häuften sich.

Inzwischen sind wir rasant im 21. Jahrhundert angekommen. Der amerikanische Onkologe und gefeierte BigData-Fan David B. Agus hat 2012 «The End of Illness» prognostiziert, wenn der Homo sapiens seine Doppelhelix entschlüsseln und nötigenfalls korrigieren lässt. In seinem Bestseller verrät Agus das eigene genetische

Die pränatale Diagnostik wurde perfektioniert, ethische Konflikte häuften sich.

Profil mit pseudo-präzisen Prognosen: 36\% lifetime risk of obesity - seine Personenwaage mit Digitalanzeige mahnte schon lange zuvor. 3,9\% Risiko eines Aneurysmas! Wurde die Angst vor exakt 26 persönlichen Risiken weggespült durch reichlich fliessende Buchhonorare?

Nicht nur Pensionierte haben Mühe, die sich rasch folgenden Erkenntnisse und Methoden der Genomik und deren Fachbegriffe mitzuerfassen. Eine neue, bisher nur online verfügbare Publikation der SAMW ermöglicht aber allen Lernwilligen in der Aus-, Weiter- und lebenslangen Fortbildung ein nützliches Nach(t)studium [1].

In 16 Kapiteln werden auf 120 Seiten die genetischen, medizinischen, psychologischen, ökonomischen, ethischen, rechtlichen, soziologischen und informationstechnischen Aspekte dargelegt. Optimistischen Erwartungen folgen kritische Einwendungen. Kapitel 8 (Omics-Technologien) und ein Glossar definieren neuere Begriffe. Nicht erwähnt wird die CRISPR/Cas-Methode, die revolutionäre «Gen-Schere».
Auch die SÄZ hat 2019 geholfen, Wissenslücken aufzudecken und zu schliessen [2]: 8239 Antworten des ärztlichen Nachwuchses an Weiterbildungsstätten (Rücklauf 70\%) und 1550 (Rücklauf 95\%) ihrer Vorgesetzten belegen, wie gross der Bedarf an Genomik-Informationen im Hinblick auf eine personalisierte Medizin bei den Klinikärzten ist. Das medizinische Jungvolk wünscht mehrheitlich eine neue Berufsgattung «Genetic Counselor».

Der emeritierte Professor für Medizinische Genetik am Universitätsspital Basel hinterfragt eine Vision der

\section{Das medizinische Jungvolk wünscht eine neue Berufsgattung "Genetic Counselor».}

genomischen Medizin, routinemässig bei jedem $\mathrm{Pa}-$ tienten das gesamte Genom zu sequenzieren [3]. Genomik und genetische Beratung werden zu einem Thema für die gesamte Ärzteschaft. Er verweist auf noch ungelöste Fragen im Bundesgesetz über genetische Untersuchungen beim Menschen (GUMG) vom 15. Juni 2018.

Bereits werden in minutiös getakteten Sprechstunden die «Malades au petit papier» und googelnden Besserwisser von DNA-Selfies verdrängt. Neugierige Consumer schicken ihren Speichel direkt einem DTC-Institut, das persönliche Erbanlagen für gutes Geld in genialen Nanopore-Automaten sequenziert und orakelhaft kommentiert. Partnersuche-Institute vermitteln «Männer mit Speuz» und (fast) reinrassige Frauen mit blaublütigen Ur-Ur-Ahnen, deren genetische Spuren sich für SFR 599.- bis zum Iceman Ötzi zurückverfolgen lassen.

Das GUMG verlangt, dass genetische Untersuchungen nur nach Zustimmung der Betroffenen erfolgen dürfen, von spezialisierten Ärzten angeordnet und kommentiert, in zertifizierten Labors durchgeführt. DTCWerbung für medizinische Abklärungen ist verboten, der Datenschutz in Art. 10 genau geregelt. Art. 8 sichert ein Recht auf Nichtwissen und laut Art. 9 sollen ungefragte Überschussinformationen vermieden werden. Art. 9 soll nun auch hier gelten. Der nächste Welt-DNATag wird am 25. April 2020 gefeiert.

Literatur

1 Schweizerische Akademie der Medizinischen Wissenschaften. Per sonalisierte Medizin. Grundlagen für die interprofessionelle Aus-, Weiter- und Fortbildung von Gesundheitsfachleuten (2019). samw. ch/grundlagen-personalisierte-medizin (Stand: 28.01.2020).

2 Bearth A, Burgermeister LC, Bauer W, Sütterlin B, Siegrist M. Personalisierte Medizin: Umfrageresultate 2018. Schweiz Ärzteztg. 2019;100(38):1256-9.

3 Müller H. Genomik - Herausforderungen im ärztlichen Alltag. Schweiz Ärzteztg. 2019;100(47):1583-5. 